\title{
Helicobacter pylori: Not just a Gastric Infection
}

Mohamed H Emara

Hepatology, Gastroenterology and Infectious Diseases. Faculty of Medicine, Kafrelsheih University, Egypt

E mail:

Emara_20007@yahoo. $\underline{\text { com, }}$

Mohamed_emara@me d.kfs.edu.eg

Key words:

Helicobacter pylori; Itching, Gastric

\section{INTRODUCTION}

Mobile:

$+201002724482$

Helicobacter $(H)$ pylori is a gram negative spiral flagellated bacteria and is the most prevalent infection around the globe. Higher prevalence rates are linked to low socio-economic standards and hence it is more prevalent in the developing countries. Although this gram negative spiral bacteria inhabits the gastro-duodenal mucosa it is linked to gastric and many extra-gastric disease states. The diversity of presentations (Figure 1) among $H$ pylori infected subjects are due to a complex interplay between bacterial, environmental, and host genetic factors [1]. The spectrum of gastro-duodenal affection mostly passes through asymptomatic infection. Furthermore, with time the infection evolve to acute and chronic gastritis, peptic ulcer, and minority of patients are prone to the most serious sequel, the gastric cancer (Figure 1). $H$ pylori is classified as class I carcinogen by the WHO [2] and hence identification and eradication of the infection is recommended for subgroups of patients as per the current practice guidelines $[\mathbf{3 , 4}]$.

The list of extra-gastric associations is long and diverse. In fact, $H$ pylori have been linked to many metabolic, cardiac, neurological, allergic, ocular, haematological, dermatological, and hepatobiliary diseases and the list is extending [5]. It seems that these associations have been over estimated because the evidence linking $H$ pylori infection to these diseases depends on epidemiological studies. Consequently, the current practice guidelines recommend testing for and eradication of $H$ pylori among subgroup of patients including patients with obscure iron deficiency anemia, primary immune thrombocytopenia (ITP), and vitamin B12 deficiency $[3,4]$. Sticking to these recommendations would limit the over testing for $H$ pylori in many diseases that lacks an etiological association with $H$ pylori infection [6].

There is a trend among dermatologists in our community to test patients with persistent itching for $\mathrm{HCV}$ and $H$ pylori after exclusion of the local and the common systemic causes owing to the high prevalence of both infections in our community. Although the mechanism of skin involvement among patients with $\mathrm{HCV}$ infection seems related to both direct immune mediated mechanisms and to indirect mechanisms through the development of cirrhosis [7,8], the mechanism of skin affection among patients with $H$ pylori infection is not understood. However, the autoimmune mechanism is the most likely. It seems that following the prolonged infection with $H$ pylori an interaction with the host immune system do occur. $H$ pylori trigger antigens that cross-react with $\mathrm{T}$ cells and provoke autoantibodies with the final result loss of tolerance to self-antigens in the skin [9].

Salama et al., in the current issue of Afro-Egypt $J$ Infect Endem Dis published an interesting article focusing the prevalence of $H$ pylori among patients with persistent itching. The authors reported a prevalence of $H$ pylori among 130 out of 280 patients $(46.4 \%)$ of persistent itching after exclusion of the common 
causes of itching. The authors reported $60 \%$ complete response defined as disappearance of itching after 2-weeks of $H$ pylori treatment. Furthermore, $20 \%$ of patients reported partial improvement while $20 \%$ did not improve in comparison to $0 \%$ among the $H$ pylori negative group treated with anti-histaminics. The authors reported also Ig E levels to be significantly higher among $H$ pylori negative cases ruling out the allergic mechanism as a cause of skin affection in $H$ pylori infected subjects.

The power of the current study is that is focuses a group of patients we usually face in our daily practice. Furthermore, the relatively high number of patients recruited empower the validity of the study. The findings of the current study present new insights in the spectrum of extra-gastric manifestations attributed to $H$ pylori infection.
The weakness point of the current study is its inability to establish a causal relationship between the persistent itching and $H$ pylori infection. Similar to another study carried out by Kandyl et al. [10], where $H$ pylori eradication was not confirmed after the course of treatment. It would have an impact if the pattern of response among $H$ pylori group was compared to the eradication of the infection. The relation between the treatment regimen and the pattern of response was also lacking.

Future multicenter studies recruiting large number of patients linking the patterns of response to the eradication of $H$ pylori may elucidate the actual relationship between $H$ pylori infection and persistent itching.

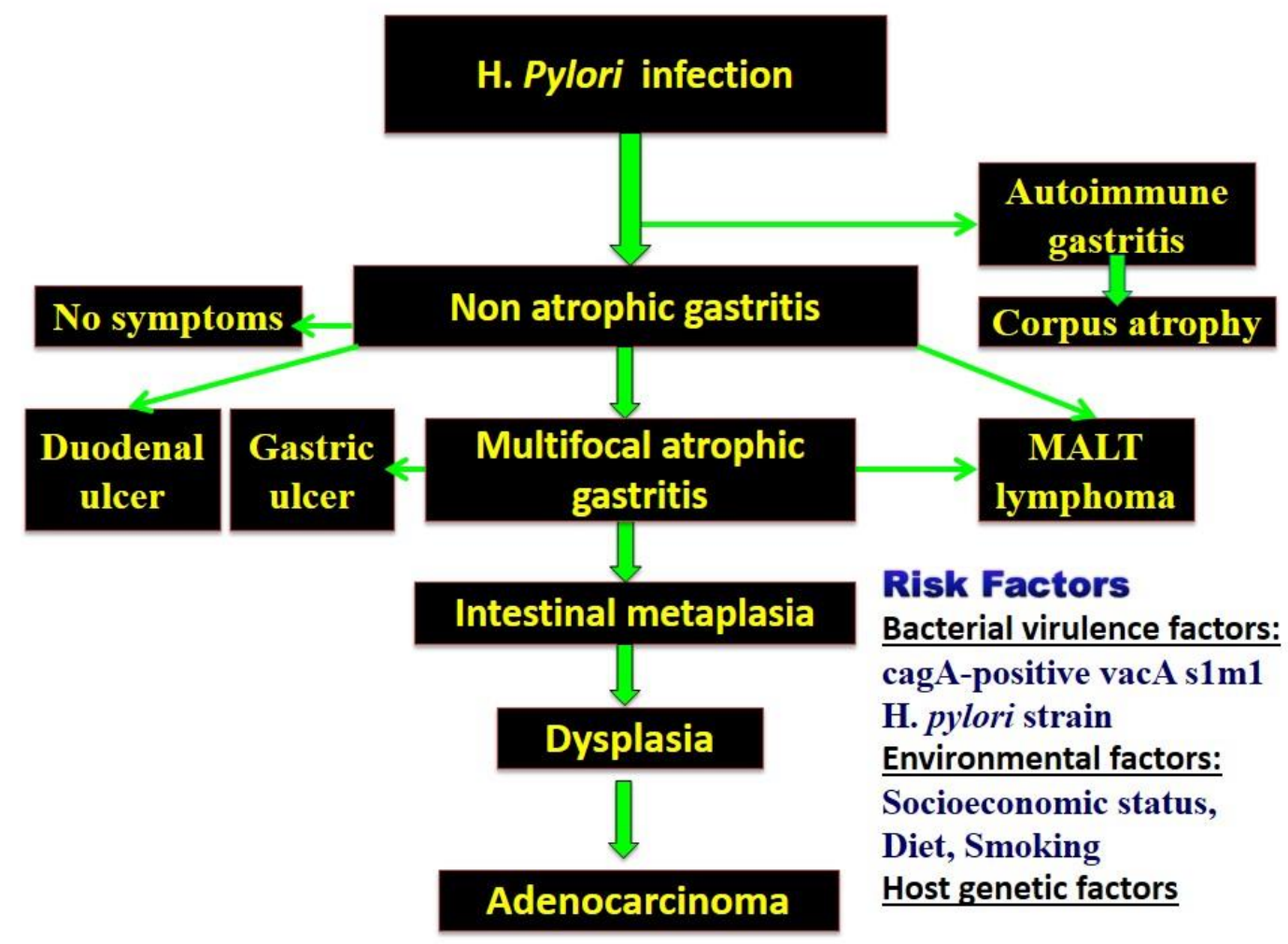

Fig. (1): The natural history of $H$ pylori infection. Most of the infection is acquired during childhood and mostly remain asymptomatic. The progression of infection is affected by complex interplay between bacterial, environmental, and host genetic factors.

\section{REFERENCES}

1. Kusters JG, van Vliet AH, Kuipers EJ. Pathogenesis of Helicobacter pylori infection. Clin Microbiol Rev. 2006; 19(3):449-90.

2. Anonymous Live flukes and Helicobacter pylori. IARC Working Group on the Evaluation of Carcinogenic Risks to Humans, Lyon, 7-14 June 1994. IARC Monogr. Eval. Carcinog. Risks Hum. 1994; 61: 1-241.

3. Malfertheiner P, Megraud F, O'Morain CA, Atherton J, Axon AT, Bazzoli F, et al. Management of Helicobacter pylori infection-- 
the Maastricht IV/ Florence Consensus Report. Gut. 2012; 61(5): 646-64.

4. Alboraie M, Elhossary W, Aly OA, Abbas B, Abdelsalam L, Ghaith D, et al. Egyptian recommendations for management of Helicobacter pylori infection: 2018 report. Arab J Gastroenterol. 2019 Sep; 20(3):175-179.

5. Gravina AG, Priadko K, Ciamarra P, Granata L, Facchiano A, Miranda A, et al. Extra-Gastric Manifestations of Helicobacter pylori Infection. J Clin Med. 2020 30; 9(12):3887.

6. Chey WD, Leontiadis GI, Howden CW, Moss SF. ACG Clinical Guideline: Treatment of Helicobacter pylori Infection. Am J Gastroenterol. 2017; 112(2): 212-239.
7. Dedania B, Wu GY. Dermatologic Extrahepatic Manifestations of Hepatitis C. J Clin Transl Hepatol. 2015 28;3(2):127-33.

8. Soliman AM, El hawari SA, Refaey MM, Ahmed NH, Emara MH. Extrahepatic Manifestations of Hepatitis C Virus: An Extending List. Afro-Egypt J Infect Endem Dis 2012; 2(1): 36-53.

9. Magen E, Delgado JS. Helicobacter pylori and skin autoimmune diseases. World $J$ Gastroenterol. 2014 14;20(6):1510-6.

10. Kandyil R, Satya NS, Swerlick RA. Chronic pruritus associated with Helicobacter pylori. $J$ Cutan Med Surg. 2002;6(2):103-8. 